\title{
Educação intercultural e formação de professores em contexto espanhol para alunos imigrantes'
}

Doris Cristina Vicente da Silva Matos"

Cristina Goenechea Permisán"II

I-Trabalho desenvolvido com bolsa de pesquisa da Fundación Carolina no programa de mobilidade de professores de universidades públicas brasileiras. A pesquisa foi desenvolvida na Universidade de Cádis, Espanha, no grupo de investigación Eduardo Benot (HUM 230), em conjunto com o Grupo de Pesquisa DinterLin: Diálogos Interculturais e Linguísticos, da Universidade Federal de Sergipe, Brasil.

II- Universidade Federal de Sergipe, Aracaju, SE, Brasil.

Contato: profadoris_ufs@yahoo.com.br

III- Universidad de Cádiz, Cádis, Espanha. Contato: cristina.goenechea@uca.es

\section{Resumo}

Este trabalho convida à discussão sobre a relação entre a educação intercultural e a formação de professores em contexto multicultural e multilíngue. Partimos do fenômeno das migrações, que tem ocupado lugar de destaque no cenário mundial e, do mosaico cultural decorrente desse fenômeno, surgem conflitos de ordem política, ideológica, religiosa, étnica, cultural, dentre outros. Investigamos o papel da escola e dos professores em meio ao cenário estabelecido e temos como objetivo apresentar os resultados de uma pesquisa realizada em contexto espanhol, com professores que recebem alunos imigrantes que, em sua maioria, não sabem o idioma local e precisam aprendê-lo para integrar-se ao ambiente escolar, assim como à sociedade em que estão inseridos. Para tanto, a metodologia utilizada seguiu os princípios da pesquisa mista, utilizando as abordagens qualitativa e quantitativa, de paradigma interpretativista, para a análise dos dados obtidos por meio de questionários e transcrições de reuniões dos grupos de discussão. A coleta foi realizada com professores que atuam nas Aulas Temporales de Adaptación Lingüística (ATAL) situadas na provincia de Cádis, dentro da comunidade autônoma da Andaluzia, na Espanha. Os resultados evidenciaram a demanda, por parte dos professores, da realização de ações pedagógicas orientadas para a formação com base na educação intercultural, indicando que as discussões sobre essa temática são importantes para a construção de uma escola que promova e entenda o encontro com o outro como parte das relações interculturais.

\section{Palavras-chave}

Educação intercultural - Formação de professores - Contextos multilíngues - Imigração - Adaptação linguística. 


\title{
Intercultural education and teacher education in the current context of immigrant students in Spain'
}

\author{
Doris Cristina Vicente da Silva Matos" \\ Cristina Goenechea Permisán"II
}

I-Trabalho desenvolvido com bolsa de pesquisa da Fundación Carolina no programa de mobilidade de professores de universidades públicas brasileiras. A pesquisa foi desenvolvida na Universidade de Cádis, Espanha, no grupo de investigación Eduardo Benot (HUM 230), em conjunto com o Grupo de Pesquisa DInterLin: Diálogos Interculturais e Linguísticos, da Universidade Federal de Sergipe, Brasil.

II- Universidade Federal de Sergipe, Aracaju, SE, Brasil.

Contact: profadoris_ufs@yahoo.com.br

III- Universidad de Cádiz, Cádis, Espanha.

Contact: cristina.goenechea@uca.es

\begin{abstract}
This paper is an invitation to discuss the relation between intercultural education and teacher education in a multicultural and multilingual context. Our starting points are migration - which has been an important issue in the world - and the cultural variety arising from this phenomenon, which generates political, ideological, ethnic and cultural conflicts. We have researched the role of schools and teachers in the current scenario and aim to present the results of a study conducted in Spain with teachers who receive immigrant students. Most of these students do not speak the local language and need to learn it to integrate into the school environment and into society. As for methodology, we have followed mixed research principles, using quantitative and qualitative approaches, of the interpretive paradigm, to analyze the data obtained through questionnaires and transcriptions of discussion group meetings. The data was collected from the teachers who work on Aulas Temporales de Adaptación Lingüistica (ATAL - Language Adaptation Temporary Classes) in the province of Cadiz, in the autonomous region of Andalucia, Spain. The results obtained evidenced that there is a demand on teachers' part for educational actions focused on intercultural education. This indicates that the discussion on this matter is important for the development of schools that encourage and understand meeting the other as part of intercultural relations.
\end{abstract}

\section{Keywords}

Intercultural education - Teacher education - Multilingual contexts - Immigration-Linguistic adaptation. 


\section{Considerações iniciais}

A diversidade presente nas sociedades atuais faz com que seja necessário dotar a educação de um caráter intercultural, que contribua para a transformação de uma sociedade multicultural, na qual coexistem diversas culturas, em uma sociedade intercultural, na qual se produza um verdadeiro intercâmbio que transforme tanto os grupos majoritários como os minoritários. Consideramos o conceito de cultura dentro da perspectiva dos estudos culturais, que se ocupam de seus diferentes aspectos, e se caracterizam por ser interdisciplinares ao dialogar com outros campos do saber. Na Espanha, o desenvolvimento da interculturalidade no âmbito educativo está estreitamente relacionado com a chegada da população imigrante, principalmente desde a década de 90. À diferença de outros países europeus, como França, Inglaterra ou Alemanha, que recebiam imigrantes há várias décadas, a Espanha se transforma de país de emigração a país de imigração nos anos 90.

Desde então, começa a ser estudada essa temática e a se introduzir essa perspectiva pouco a pouco na elaboração de planos, normas e projetos educativos. Anteriormente existia o precedente da população cigana, que está presente há sete séculos na Espanha, mas que ainda na atualidade encontra dificuldades como o escasso reconhecimento de sua cultura de origem no sistema educacional, a alta concentração destes alunos em determinadas escolas, a falta de expectativas e o fracasso escolar.

0 contexto que descrevemos brevemente traz a inquietação sobre a preparação das escolas e, consequentemente, dos professores em formar cidadãos capazes de viver em uma sociedade com estas características. Para que se ofereçam propostas de resistência à tendência ao individualismo e à exclusão dos mais desfavorecidos, pode-se entender que a educação intercultural seja um elemento na luta contra uma escola e sociedade excludentes, nas quais se encontram inseridos os migrantes, seja qual for a região de que se originem.
Pensando nesse contexto, este trabalho tem como objetivo apresentar os resultados de uma pesquisa realizada em contexto espanhol, com professores que recebem alunos imigrantes que, em sua maioria, não sabem o idioma local e precisam aprendê-lo para integrar-se ao ambiente escolar, assim como à sociedade em que estão inseridos. Os dados foram coletados por meio de professores que atuam nas Aulas Temporales de Adaptación Lingüística (ATAL) situadas na província de Cádis, dentro da comunidade autônoma da Andaluzia, na Espanha.

Esta pesquisa nasce da interseção de dois projetos: o primeiro, finalizado em 2009, intitulado Estudio de la atención educativa prestada al alumnado inmigrante en las ATAL de Cádiz, financiado pela Dirección General de Coordinación de Políticas Migratorias da Consejería de Gobernación de la Junta de Andalucía, desenvolvido na Universidade de Cádis. 0 segundo, que está em andamento e foi iniciado em 2014, intitulado Construyendo diferencias en las escuelas, estudio de las trayectorias de las ATAL en Andalucía, de su profesorado y su alumnado, financiado pelo Ministerio de Economía y Competitividad en el marco del Plan Nacional de $\mathrm{I}+\mathrm{D}+\mathrm{I}^{1}$, desenvolvido na Universidade de Granada.

Partimos, neste trabalho, de um recorte que utiliza dados de ambas as pesquisas, triangulados em 2016 durante período de investigação financiado pela Fundação Carolina e desenvolvida na Universidade de Cádis, Espanha, no Grupo de Pesquisa Eduardo Benot, em conjunto com o Grupo de Pesquisa DInterLin: Diálogos Interculturais e Linguísticos, da Universidade Federal de Sergipe, Brasil. Pretendemos, com a base de dados obtidos, dar continuidade em relação ao objeto de estudo, ampliando o conhecimento sobre o contexto das ATAL na província de Cádis.

1- 0 Plano Nacional de $|+D+|$ é um dos projetos de investigação desenvolvimento e inovação do programa estatal de investigação, desenvolvimento e inovação, orientados às necessidades da sociedade em que está inserido, para o período de 2013 a 2016 


\section{Educação intercultural e imigração na Espanha}

Segundo dados do Ministério da Educação, Cultura e Esporte da Espanha, no curso 2014-2015 do país, 8,5\% dos alunos eram estrangeiros. Sobre sua nacionalidade de origem, se destacam os alunos procedentes da Europa (31,7\%), junto com a África (30,6\%), e ambos superam os procedentes da América Central e do Sul (27,7\%), sendo que este último era um grupo majoritário. Por países, destacamse Marrocos (172.236 alunos), Romênia (99.400), Equador (44.985), China (33.182) e Colômbia (27.944 alunos). Entretanto, não dispomos de uma cifra exata da população cigana, pois o censo somente registra a nacionalidadee, nesse caso, tratam-se de espanhóis. A Fundación Secretariado Gitano estima que por volta de 2\% da população espanhola é cigana. Assim, tomados em conjunto, cerca de 10\% dos alunos pertence a uma cultura que não é a majoritária. Por outro lado, ainda que não aprofundemos esse tema, convém lembrar que nenhuma cultura é monolítica, uniforme, sendo sempre um reducionismo falar de culturas e não de indivíduos, que as recriam ao vivêlas. A diversidade cultural não se esgota na nacionalidade, ainda que tenhamos que recorrer a esses dados para dimensionar o fenômeno.

Situar-se em uma perspectiva intercultural implica acreditar numa construção de sociedade mais aberta, caracterizada pelo diálogo, convivência e intercâmbio. Assim expresa Besalú (2002, p. 71), quando afirma que:

\section{[...] a educação intercultural é} fundamentalmente uma atitude e um comportamento relativo ao tipo de relações que ocorrem entre as culturas que convivem em um ambiente determinado. Propõe-se atender às necessidades afetivas, cognitivas, sociais e culturais dos indivíduos e dos grupos possibilitando que cada cultura expresse sua solução aos problemas comuns. É um meio para promover a comunicação entre as pessoas e para favorecer as atitudes de abertura em plano de igualdade. ${ }^{2}$

A educação intercultural promove valores como a igualdade, o sentido comunitário, a aceitação e o respeito pelo outro, o respeito aos direitos humanos ou à solidariedade. Tanto esses princípios como o conceito de educação intercultural se encontram fortemente enraizados, como afirma López Reillo (2006), nas propostas educativas que pretendem garantir o direito de todo aluno a uma educação de qualidade, como a educação democrática, a educação inclusiva, a educação em valores e a educação para a cidadania.

Entre as características da educação para a cidadanía intercultural, destacam-se as seguintes (JIMÉNEZ; GOENECHEA, 2014):

a) fundamenta-se no reconhecimento e valorização da diversidade cultural;

b) é relevante para todos os alunos;

c) protege a identidade cultural dos alunos, especialmente dos minoritários;

d) defende a igualdade de oportunidades;

e) luta contra o racismo, a discriminação e os preconceitos. Paralelamente promove a formação de valores e atitudes positivas para a diversidade cultural;

f) entende o conflito como elemento positivo e necessário para a convivência;

g) requer uma revisão de currículo e modificações nas metodologias de ensino e recursos didáticos;

h) contempla medidas educativas específicas para os alunos imigrantes que necessitem;

i) supõe mudanças sociais profundas que não se limitem à escola.

Entendemos que uma formação baseada nos princípios da educação intercultural é essencial para que os professores possam desenvolver estratégias que promovam um ambiente aberto à diversidade que seja um elemento na luta contra uma escola e sociedade excludentes,

2- Todas as citações em espanhol foram traduzidas para o português pelas autoras. 
nas quais se encontram inseridos os migrantes, em que a adaptação linguística pode ser um obstáculo à integração.

\section{Políticas de atenção para alunos imigrantes na Espanha}

0 sistema educativo espanhol se transformou com a incorporação de alunos estrangeiros. A seguir veremos quais medidas foram tomadas como consequência da incorporação destes novos grupos na escola. Primeiro, é necessário aclarar que na Espanha todos os menores com idade de cursar a educação obrigatória têm direito a uma educação pública e gratuita. Inclusive nos casos em que o menor se encontre em situação irregular, que não tenha os documentos de residência regularizados, tem direito e obrigação de ser escolarizado durante a etapa da educação obrigatória.

A legislação educativa espanhola sempre incluiu os estrangeiros como possíveis beneficiários de políticas compensatórias ao inseri-los na categoria de alunos com necessidades educativas especiais, seja por sua origem étnica, como parte dos alunos em situação social desfavorecida, ou por sua incorporação tardia ao sistema educativo. Entretanto, estas intervenções não tiveram um efeito significativo nos resultados escolares, que continuam sendo mais baixos entre os alunos estrangeiros. Essas medidas não conseguem compensar o efeito ao menos estatístico - produzido pela etnia e a classe social, motivo pelo qual esta segregação temporal (em ATAL, aulas de enlace, grupos de diversificación, aulas de apoyo, centros de compensatoria etc.) pode se converter em permanente, ao dificultar a integração de todas essas pessoas em âmbito trabalhista e social.

A presença de alunos estrangeiros nas escolas é, como explicamos anteriormente, o principal fator desencadeante dos planejamentos da educação intercultural no sistema educativo espanhol, evoluindo desde sua ausência inicial, à sua consideração posterior dentro das políticas compensatórias. Essas realidades vão ser determinantes para o modelo de resposta pelo qual as escolas optam, ao se desenvolverem mais como reação à presença de imigrantes nas aulas por meio de medidas compensatórias, do que como uma revisão da inadequação dos supostos homogeneizadores e etnocêntricos sobre os quais está balizado o próprio sistema, além de buscar respostas dentro do marco e das medidas de atenção à diversidade, equidade e inclusão. A partir da Lei Orgânica de Educação (2006), começa a ser introduzida uma visão menos parcial, mais intercultural, que valoriza um pouco mais a cultura de origem desses alunos e começa a se distanciar da teoria do déficit, de caráter fortemente assimilacionista. Esta evolução ocorreu mais nas normas e nas teorias do que nas práticas e ainda não podemos afırmar que tenha uma repercussão muito ampla em âmbito educativo.

Como as escolas mudaram sua forma de atuação com a chegada da população estrangeira? Devemos reconhecer que a maioria das escolas não modificaram quase nada, seja porque não possuem alunos estrangeiros, seja porque os têm, mas são hispanofalantes e, portanto, não se considera necessário tomar medidas por não haver dificuldades linguísticas. Inclusive aquelas escolas que têm uma presença alta de alunos estrangeiros não fazem mudanças profundas. As pesquisas, ocorridas em escolas consideradas interculturais, demonstram que o grau de desenvolvimento da educação intercultural fica nos níveis mais baixos. Assim, por exemplo, Aguaded et al. (2010, p. 197) em pesquisa realizada em escolas com alta presença de imigrantes na cidade de Granada, conclui que:

[...] nenhuma das atividades é trabalhada desde as experiências, diferenças, interesses e expectativas de todos, pois a interculturalidade não se aborda desde todo sistema educativo e para todos os membros que participam dele, mas desde programas ou atividades pontuais que poderiam integrar-se em propostas curriculares com 
caráter assimilacionista, separatista e, no melhor dos casos, integrador.

Em geral, as ações que as escolas fazem com maior frequência são:

- planos de acolhida, que incluem sinalização na escola, informação sobre o sistema educativo em diversos idiomas e figuras como o aluno tutor ou a família de acolhida, que ajudam aos recém-chegados;

- aulas linguísticas para a aprendizagem da língua veicular, sempre enfocadas desde a teoria do déficit, desde o bilinguismo substrativo, no qual não se valoriza a manutenção da língua materna desses alunos;

- medidas dirigidas a reduzir a defasagem curricular dos recém-chegados: escolarização de um curso abaixo do que corresponderia aos alunos pela idade, apoio dentro ou fora da aula e diversifıcação curricular;

- atividades multiculturais. Programas de interculturalidade fracos, com atividades pontuais que introduzem uma mostra de costumes das culturas presentes nas escolas, por meio de semanas interculturais ou atividades do tipo danças ou jogos do mundo, o que se denominou pedagogía del cous cous.

Convém recordar que seria necessário trabalhar a interculturalidade em todos os colégios e não somente naqueles que têm alunos estrangeiros. Todas as crianças vão viver num contexto multicultural, assim todos necessitam estar preparados para conviver com pessoas culturalmente diversas.

\section{Aulas temporárias de adaptação linguística (ATAL) no contexto andaluz: o caso da província de Cádis}

Quando um sistema educativo começa a receber alunos estrangeiros, o primeiro desafio que enfrenta é o do ensino da língua veicular, para que possam integrar-se nas aulas e acompanhar o currículo da escola. Quando, nos anos noventa, começou a chegar na Espanha um grande número de população estrangeira, não existia nenhum recurso educativo para que os alunos que não falassem espanhol aprendessem a língua. Inicialmente, as escolas responderam a esta chegada imprevista integrando os alunos estrangeiros que não falavam espanhol nos programas de apoio que já existiam para os alunos com dificuldades de aprendizagem ou outras necessidades educativas, ou também recorrendo à boa vontade dos professores, que ministravam aulas de espanhol em suas horas livres. Com o passar do tempo e o aumento progressivo da imigração foi necessária uma resposta estrutural, mais organizada, com recursos e profissionais com formação específica.

É nesse contexto que nascem - por volta do ano 2000 - as chamadas aulas lingüísticas, que foram implantadas nas diversas comunidades autônomas espanholas com distintos formatos e denominações: Aulas Temporales de Adaptación Lingüística (ATAL), na Andaluzia e Extremadura; Aulas de Acogida na Catalunha, Ilhas Baleares e Múrcia; Aulas Temporales de Inmersión Lingüística (ATIL), em Astúrias; Aulas de Inmersión Lingüística (AIL), em Navarra e La Rioja; Aulas de Adaptación Lingüística y Social (Aulas ALISO), em Castela e Leão; Grupos de Adaptación de la Competencia Curricular e Grupos de Adquisición de las Lenguas, na Galícia; Programas de Acogida al Sistema Educativo (PASE), na Comunidade Valenciana; Programa de Refuerzo Lingüístico, no País Vasco; Aulas de Enlace, em Madrid.

Essa diversidade de respostas educativas ao fenômeno da imigração é devida ao fato de a Espanha ser um país descentralizado e as esferas educativas se dividirem entre o nível estatal (Ministerio de Educación) e o autonômo ou regional (Consejería de Educación, no caso da Andaluzia). Essas aulas possuem aspectos diferentes em cada região, mas dividem uma série de características como «seu caráter intermediário, aberto, intensivo e flexível» (GRAÑERAS et al., 2007, p. 163). Realmente, as diferenças entre os modelos implementados pelas distintas comunidades autônomas são tão grandes que dificilmente podemos encontrar propriedades comuns a todas elas. 
Em âmbito estatal, a Lei Orgânica 2/2006, de 3 de maio, de educação, em seus artigos 79.1 e 79.2, já estabelecia a responsabilidade das administrações de favorecer a incorporação ao sistema educativo dos alunos de inserção tardia com "programas específicos para os alunos que apresentem graves carências linguísticas" (ESPAÑA, 2006) cujo desenvolvimento será "simultâneo à escolarização dos alunos nos grupos ordinários, conforme o nível e evolução de sua aprendizagem" (ESPAÑA, 2006). Seguindo essa determinação, a Lei Orgânica 8/2013, para a melhoria da qualidade educativa (LOMCE), mantém essas obrigações nos mesmos termos.

Neste trabalho, nos centramos nas Aulas Temporales de Adaptación Lingüística (ATAL) que tiveram início na Andaluzia entre os anos de 2001-2002, mas não tiveram uma regulamentação específica até 2007. Tratase da Ordem de 15 de janeiro de 2007, por meio da qual são regulamentadas as medidas e ações a serm desenvolvidas para atender aos alunos imigrantes e, especialmente, às Aulas Temporales de Adaptación Lingüística.

Trata-se do recurso mais importante iniciado na Andaluzia para atender aos alunos estrangeiros e talvez o mais necessário. A falta de domínio da língua constitui um obstáculo para a educação que deve ser superado para integração tanto na escola como na sociedade. Constatou-se que:

A aquisição da língua da escola, apesar de ser instrumento chave para favorecer a integração, é, hoje em dia, para os alunos marroquinos um dos maiores obstáculos no processo de integração $(42,2 \%)$; seguido de fazer amigos, estando este último intimamente relacionado com o primeiro (TERRÓN-CARO; PALMA, 2015, p. 114).

Essa afırmação seria igualmente válida para os demais alunos estrangeiros, especialmente aqueles cuja língua difere muito do espanhol.

Segundo dados do Conselho de Educação, Cultura e Esporte da Espanha, no curso 2001-
2002, havia 64 docentes das ATAL em toda Andaluzia e nos cursos posteriores continuou aumentando seu número até alcançar 315 no curso 2008-2009. Depois, o número foi reduzido devido à crise econômica e a menor chegada de alunos estrangeiros de nova incorporação. No curso 2014-2015, havia em toda Andaluzia 221 professores das ATAL, a maioria dos quais atendia a alunos escolarizados em um máximo de cinco escolas.

Estudaremos esse recurso na província de Cádis, na qual ocorreram as pesquisas. No curso 2014-15, dez professores(as) atenderam a 184 alunos(as) em 53 centros (32 de Primária e 21 de Secundária) de toda a província de Cádis. Todas as ATAL exceto uma atendem tanto centros de educação primária como de secundária. A professora que menos centros atende trabalha em quatro escolas e a que mais, em sete; sendo a média de cinco escolas. 0 número de alunos(as) por professor(a) oscila entre 24 e quinze, sendo dezoito a média. A maior parte dos alunos de ATAL na província de Cádis (59,2\%, 109 pessoas) cursa a educação primária; enquanto que os 40,7\% restantes (75 alunos(as)) cursam a educação secudária obrigatória (ESO) e o programa de qualificação profissional inicial (PCPI).

A educação primária compreende alunos de seis a doze anos; a ESO compreende entre 12 e 16 anos; o PCPI, entre 16 e 17 anos. Atualmente este último é denominado de formação profissional básica e tem a finalidade de favorecer a inserção social, educativa e de trabalho dos jovens que abandonam o sistema educativo sem o título da educação secundária obrigatória.

Os destinatários desse recurso são os alunos recém-chegados que não dominam o espanhol. As ATAL atendem aos alunos a partir do segundo ciclo da primária (desde os oito anos) e até o final da ESO (dezesseis anos), já que se entende que nas idades inferiores aos oito anos os alunos aprendem de uma maneira "natural", por imersão na aula regular. 0 número máximo de alunos nas ATAL está limitado a doze. Pela 
regra geral, os alunos podem assistir a essas aulas durante o primero ano de sua escolarização, ainda que excepcionalmente possa ser autorizada sua assistência durante mais um ano se persistirem as dificuldades com o idioma.

Desde nosso ponto de vista, dar um apoio de dez ou quinze horas semanais durante um ou dois anos é insuficiente. Os estudos mostram que esses alunos demoram entre um e dois anos para desenvolver as habilidades orais na segunda língua e é entre cinco ou seis anos de vivência no país quando usam as habilidades linguísticas acadêmicas de modo semelhante a seus pares nacionais. São essas habilidades acadêmicas, mais complexas e elaboradas, as que necessitam ser desenvolvidas para se ter êxito na escola.

De maneira geral, são atribuídas aos professores das ATAL todas aquelas funções relacionadas com o atendimento direto e o acompanhamento dos alunos imigrantes com deficiências no conhecimento do espanhol como língua veicular no processo de ensino/aprendizagem. Entre as funções específicas destacamos:

a) ensinar a língua espanhola com a suficiência necessária para a correta integração dos alunos imigrantes em seu entorno escolar e social;

b) atender às dificuldades de aprendizagem dos alunos matriculados nas ATAL pelo desconhecimento do espanhol como língua veicular;

c) facilitar a integração dos alunos em seu contexto escolar e social, potencializando suas habilidades e incentivando sua participação nas atividades organizadas pelas próprias escolas e pela comunidade;

d) colaborar com as chefias de estudos, que integram parte da equipe de direção de cada escola, junto ao diretor e o secretário, das escolas atendidas na necessária coordenação com os outros professores;

e) colaborar com os professores encarregados das tutorias na manutenção da comunicação com as famílias dos alunos atendidos nas ATAL; f) facilitar aos professores das escolas atendidas orientações metodológicas e materiais sobre o ensino do espanhol como segunda língua.

Além disso, devem elaborar as programações das ATAL, redigir um relatório de cada um dos alunos e alunas atendidos e elaborar um relatório final ao acabar o curso.

A norma prioriza o apoio dentro das aulas regulares e estabelece que somente quando não seja possível, o apoio será dado fora da aula. Nesses casos, nos quais se distanciem os alunos estrangeiros do seu grupo de referência, é estabelecido um máximo de dez horas semanais para crianças de primária e quinze para os de secundária. $\mathrm{Na}$ Andaluzia existem dois tipos de ATAL: as fixas, situadas em uma escola em tempo integral, em zonas que registram um elevado índice de população imigrante, sobretudo em Almeria e Málaga; e as itinerantes, nas quais o professor se desloca para atender a vários colégios de uma mesma zona ou localidade. No caso da província de Cádis, todas são itinerantes, pela dispersão da população imigrante.

A província de Cádis constitui um território singular em relação à confluência de população estrangeira. Por um lado, sua posição geográfica como ponto mais próximo ao continente africano define seu papel de porta de entrada para grande parte da população imigrante de origem magrebina e subsaariana. A maioria dos estrangeiros que chegam seguem seu caminho para outro ponto da Europa, como França ou Alemanha. Os cidadãos originários do Marrocos representam 21\% dos estrangeiros registrados em 2014 nesta província.

Por outro lado, suas boas condições climáticas e os baixos custos de produtos e serviços estão animando o assentamento de uma colônia de cidadãos da União Europeia, principalmente britânicos (5.810, 13,5\% dos estrangeiros registrados em 2014) e alemães (2.173, 5\% do total). Ao exposto se une a presença de imigrantes centro-europeus (principalmente população romena, com 3.262, $7,6 \%$ do total de estrangeiros registrados) e chineses $(1.849,4,3 \%$ do total) que assim como 
nas demais províncias andaluzas e do restante da Espanha, se assentam nesta zona em busca de oportunidades de trabalho.

Nos últimos anos está sendo incrementada também a população norte-americana, devido à ampliação do grupo militar destinado na Base Naval de Rota com motivo do estabelecimento na zona do Escudo Antimísseis. Parte desta população está se assentando fora da própia Base, principalmente nas localidades de Porto de Santa Maria e Rota, embora não representem uma cifra importante no padrão municipal.

\section{Procedimentos metodológicos}

Esta pesquisa está inserida no projeto Construyendo diferencias en las escuelas, estudio de las trayectorias de las ATAL en Andalucía, de su profesorado y su alumnado, financiado pelo Ministerio de Economía y Competitividad en el marco del Plan Nacional de I+D+I e coordenado pelo Dr. Javier García Castaño da Universidade de Granada, Espanha. Trata-se de uma investigação qualitativa, cujos principais métodos de levantamento de dados são a observação participante e a entrevista. Os objetivos do estudo são: estudar as trajetórias das ATAL, dos centros que tiveram o recurso, dos professores responsáveis e dos alunos que se beneficiaram do programa.

Atualmente em Cádis estão sendo realizadosos estudos de caso que começaram no curso 2014-2015 e que estão centrados nos docentes das ATAL. Esta investigação é uma continuidade em relação ao objeto de estudo, pois em 2007 foi realizada a pesquisa mais ampla até o momento sobre as ATAL na província de Cádis, intitulada Estudio de la atención educativa prestada al alumnado inmigrante en las ATAL de Cádiz, financiado pela Dirección General de Coordinación de Políticas Migratorias da Consejería de Gobernación de la Junta de Andalucía, por meio do Grupo de Pesquisa Eduardo Benot (HUM 230), da Universidade de Cádis, coordenado pelo Dr. Rafael Ángel Jiménez Gámez (JIMÉNEZ GÁMEZ, 2009). Consistiu em um estudo misto com uma parte quantitativa e outra qualitativa. Para a parte quantitativa, o levantamento dos dados foi realizado por meio de três questionários dirigidos a diferentes agentes (equipe de direção, tutores e professores ATAL) e a transcrição das reuniões dos grupos de discussão com estes agentes. A qualitativa estava composta por três estudos de caso de professores ATAL da província. 0 principal objetivo da pesquisa era conhecer o funcionamento dessas aulas em Cádis.

Neste trabalho, realizaremos um recorte que utiliza dados dos questionários aplicados e das transcrições das reuniões dos grupos de discussão realizados com os professores, da pesquisa iniciada em 2007 e dados da pesquisa atual. Para tanto, a metodologia utilizada seguiu os princípios da pesquisa mista, utilizando as abordagens qualitativa e quantitativa, de paradigma interpretativista.

0 recorte dos dados analisados por meio de questionários e transcrição das reuniões dos grupos de discussão centra-se em duas categorias de análise: a interculturalidade na formação dos professores das ATAL e a interculturalidade na visão dos professores. Pretendemos verificar a importância de uma formação inicial e continuada que tenha como princípio o desenvolvimento da educação intercultural focada nos diversos contextos escolares que os docentes podem encontrar e nas concepções de interculturalidade que foram evidenciadas por eles.

\section{Análise dos questionários e dos grupos de discussão}

\section{A interculturalidade na formação dos professores das ATAL}

Iniciamos a análise dos dados obtidos com o questionário e as transcrições dos grupos de discussão com o objetivo, nesta parte, de levantar e analisar as informações referentes à formação dos professores que trabalham nas ATAL da província de Cádis. Entendemos que uma formação baseada nos princípios da 
educação intercultural é essencial para que se desenvolvam estratégias que promovam um ambiente aberto à diversidade e que seja um elemento na luta contra uma escola e sociedade excludentes, nas quais se encontram inseridos os migrantes, em que a adaptação linguística pode ser um obstáculo à integração.

Um fator importante para que um docente esteja comprometido com a realidade escolar em que se encontra é a motivação. Assim, destacamos a principal razão apontada para solicitar o posto de trabalho nas ATAL no questionário: $35,7 \%$ apontou desenvolvimento pessoal e social, $35,7 \%$ compromisso com a imigração e $28,6 \%$ circunstâncias pessoais e/ou familiares; 6,3\% não declarou nenhuma razão em especial, não respondendo à pergunta. 0 compromisso com a causa da imigração e o desenvolvimento pessoal e social acarreta, muitas vezes, que os professores estejam vinculados a associações de imigração, desenvolvendo trabalhos de maneira voluntária.

A formação universitária dos entrevistados os habilita a trabalhar como docentes de educação primária no sistema espanhol, que abarca os alunos de faixa etária de seis a doze anos. Também podem realizar cursos de educação continuada que os preparem para os diversos contextos que possam encontrar. Desta feita, foram questionados sobre se receberam formação específica para trabalhar nas ATAL, ao que 81,3\% respondeu que sim, e 18,8\% que não. Três não responderam. A parte específica foi majoritariamente realizada em centros de professores (CEP), com 66,7\%, seguida de autoformação e cursos realizados na universidade, ambos os casos com 16,7\%. Sobre a quantidade de horas de capacitação continuada, 54,6\% indicou mais de 161 horas, o que indica um volume importante de tempo dedicado a esse fim. A maior parte indicou que teve um grau de satisfação e utilidade médio-alto, com 83,3\% e $75,0 \%$, respectivamente. 0 professor $\mathrm{P} 3$ comentou sobre esse tema:

Olha, todo mundo vai passando o que sabe, mas sobretudo sua didática e sua metodologia se estuda dentro da didática de todas as áreas, inclusive didática da língua. Depois por autoformação, no meu caso, por exemplo, estava desde 92 dando aulas a estrangeiros em Acoge, você se mete nisso e começa a buscar informações daqui e dali, na internet, perguntando às pessoas, inclusive nos cursos de primária, não é? Então vai se formando assim. (P3) ${ }^{3}$.

A partir desses dados, perguntamos qual seria o item mais valorizado para ser selecionado como professor das ATAL, ao que 41,7\% respondeu que era o critério de antiguidade, seguido das respostas que consideraram as necessidades do centro ou o projeto apresentado, ambos com 16,7\%. A formação específica foi considerada como o principal critério de seleção em 8,3\% dos casos. Confrontando os dados percebemos que a parte específica para o trabalho com alunos imigrantes não é o principal no momento de selecionar os docentes, portanto, a formação não seria valorizada. 0 professor P1, durante o grupo de discussão demonstrou sua insatisfação com esse critério ao comentar: "É que para a ATAL vale qualquer um. Da mesma forma pode dar aulas um professor de infantil ou um de matemática" (P1). Os demais professores também mostraram insatisfação pelo fato de não terem um tutor mais experiente ao chegar à escola, alguém que os acompanhasse nesse momento inicial.

Os dados indicam que a formação específica para trabalhar nas ATAL não é o critério mais valorizado, entretanto, os professores apontaram a sua importância: "No CEP todos os anos oferecem cursos teóricos sobre imigração em geral, que é fundamental ao princípio" (P4). Especificamente sobre o tema da educação intercultural, P1 apontou:

Eu sinto falta de um tema, porque nossa função, por exemplo, com o tema da interculturalidade estacionou, ou seja, nós somos, supõe-se, especialistas em ensino

3- Todas as falas nos grupos de discussão foram traduzidas do espanhol para o português pelas autoras. 
de língua espanhola. Não estamos especializados nem há formação específica sobre este tema. (P1).

Ao apontar que se supõe que são especialistas no ensino de língua espanhola, P1 estaria utilizando de ironia já que não há uma formação suficientemente centrada na didática de ensino de língua espanhola como segunda língua, pois muitas vezes buscam informações com os colegas mais próximos até mesmo para a preparação das aulas.

Saindo da formação e adentrando na experiência prévia que contemple a presença de alunos imigrantes em processos de ensino em aulas regulares, antes de iniciarem como professores nas ATAL, 70,5\% a possuía, e 29,4\% não teve nenhuma oportunidade anteriormente. A média de anos de experiência é ao redor de 2,4 anos. Algo parecido acontece com a experiência prévia com o ensino de espanhol como segunda língua, na qual 37,5\% tinha experiência de um ou dois anos, 18,8\% de três a cinco anos, 25,9\% de mais de cinco anos e 18,8\% não possuía experiência.

Durante o grupo de discussão, os professores foram unânimes em indicar três pressupostos básicos de formação para o trabalho no contexto das ATAL: a imigração, a interculturalidade e a didática de ensino de espanhol como língua estrangeira. Indicamos as falas mais expressivas:

Mas logo cada um de nós sai com as dúvidas de como ensinar, como se estrutura, por onde começar, pois temos que nos defender no trabalho, nisso estaremos mais ou menos formados. Eu acho que é uma coisa, este curso que falamos, quando você começa a trabalhar nas ATAL, necessita dois pilares básicos, entender o fenômeno da imigração e o da interculturalidade. (P1 - Grifos nossos).

E a didática da língua, porque é uma língua estrangeira que não é o mesmo que ensinar linguagem. Cara, vamos ver, há outro planejamento como lingua estrangeira, de fato quando vemos o inglês, quando nos deram aulas de inglês utilizaram uma metodologia diferente da que usam os ingleses para aprender inglês, veja, é que não é igual. (P3 - Grifos nossos).

A postura dos professores revela que consideram importante que, para trabalhar com alunos imigrantes nas ATAL, eles tenham formação específica que os ajude a entender a realidade em que estão inseridos. Trabalhar com alunos que possuem uma língua materna diferente da língua utilizada na escola em que estudam é realmente difícil, porém é necessário superar os obstáculos e estabelecer uma relação que considere o aspecto intercultural nesse contexto.

Coracini (2003, p. 140) aponta que "na maior parte das vezes, quando se leva em conta a existência de uma relação entre a língua materna e a língua estrangeira, essa relação é negativa", por tratarem-se de códigos e de culturas diferentes e por a língua estrangeira ser entendida, erroneamente, como complemento ao conhecimento dos alunos. É necessário superar essa visão, pois aprender uma outra língua é conhecer o outro e a si mesmo, por meio do confronto identitário e, no caso específico do entendimento da imigração, é importante olhar para as culturas que estão em interação e a língua é um dos veículos que pode estabelecer esse diálogo intercultural.

\section{A interculturalidade na visão dos professores}

Buscamos, com a análise, compreender a importância que o tema da interculturalidade possui para os professores que participaram da pesquisa, investigando se procuram desenvolver práticas que fomentem uma educação baseada em seus princípios com os alunos que participam das ATAL. É importante destacar que a educação intercultural deve ser vivenciada por todos os participantes da comunidade escolar, não somente pelos alunos imigrantes, pois pressupõe 
que as pessoas estejam interessadas em dialogar umas com as outras e entendam que, sendo a diversidade a característica mais representativa da humanidade, não deve implicar qualquer tipo de discriminação:

Do ponto de vista pedagógico, a perspectiva intercultural está baseada no reconhecimento da diversidade cultural, não somente de grupos minoritários, mas de todos os membros da sociedade. Além desse reconhecimento, as práticas desenvolvidas no contexto escolar podem auxiliar no entendimento de que a heterogeneidade que nos caracteriza deve ser vista positivamente, de maneira que se promovam o respeito e a igualdade de oportunidades, transformando as escolas em espaços de mudança social (MATOS, 2014b, p. 167).

Sendo assim, destacamos uma passagem do grupo de discussão, na qual os participantes comentavam sobre a necessidade de a escola possuir um projeto intercultural com uma pessoa encarregada de coordená-lo, como um plano de acolhimento. Um dos professores expôs que dentre todas as escolas em que trabalhava, uma delas possuía um plano de interculturalidade e acolhida em conjunto, que foi elaborado a partir dos documentos que ele facilitou à coordenadora, entretanto, não houve uma reunião para apresentar a proposta e envolver os professores, e ele nem ao menos foi consultado:

Eu acho que no tema intercultural o professor tem que se implicar, senão, o único que fazemos é colocar quatro posteres de mapas apontando de onde vem cada um dos nossos alunos, e isso ... e a viagem. Há um orçamento fantástico e viaja-se a alguns países. (P1).

A falta de diálogo entre coordenação e professores é um ponto negativo, pois para que um projeto intercultural dê certo, é preciso envolver primeiro os professores, já que serão os responsáveis por executá-lo com os alunos. Percebemos que o professor (P1) não está satisfeito com a condução do projeto pela escola e possui uma visão crítica de que, geralmente, o que acontece é a produção de cartazes com informações sobre os países dos alunos imigrantes, ou uma viagem aos países dos alunos, como por exemplo, Marrocos ou Romênia, com o orçamento conseguido por meio do projeto. Muitas vezes os professores que trabalham nas ATAL não participam das viagens, somente os que atuam nas aulas regulares.

No questionário, os professores apontaram que o perfil linguístico dos alunos que frequentam é diverso, somente um deles trabalhava com alunos que possuíam a mesma língua materna, o árabe-marroquino. Em dois casos, são duas as línguas, árabe e outra, entre chinês e inglês. Podemos afirmar que as línguas estrangeiras mais frequentes entre os alunos atendidos nas ATAL são o árabe-marroquino e o inglês, seguidos pelo romeno e chinês. Sendo língua e cultura indissociáveis, estabelecendo uma relação intrincada de pertencimento, qualquer tentativa de dissociação acarretará uma quebra dessa união (MENDES, 2007).

Outro professor (P6) comentou que conhece escolas em que os professores estão envolvidos em projetos interculturais, mas que os alunos não participavam satisfatoriamente, assim é necessário investir em outro tipo de atividades. Tais atividades aproveitariam melhor os alunos que não são imigrantes nem estrangeiros. Após esse comentário, P1 apontou: "Mas a interculturalidade é para todos, esse é o problema” (P1). Esta fala revela o entendimento de que um projeto que vise à promoção da educação intercultural não deve atender somente aos alunos imigrantes, mas a todos os alunos, pois se centrarmos a atenção em somente uma parte não ocorrerá a integração e o diálogo necessários para a construção do entendimento da diversidade cultural.

Ao serem questionados se os projetos interculturais que ocorrem nas escolas são 
eficazes para o seu trabalho, P4 informou que acredita que as escolas que solicitaram tais projetos foi porque "estão sensibilizadas com a imigração, pelo menos no meu caso, tem um grupo de alunos, inclusive de professores, que estão em associações e estão sensibilizados e fizeram coisas" (P4).É muito forte o envolvimento quando o professor está realmente interessado na realidade que vivenciam seus alunos, alguns estão envolvidos inclusive politicamente por meio de associações, e esse engajamento é importante para que o projeto obtenha êxito.

Outro ponto para pensar um projeto intercultural é sobre como ele será estruturado, quais temas devem ser abordados. Antes de definir temáticas de interesse, é preciso que o professor tenha definido o que é cultura para si próprio e, dependendo do conceito que abrace, poderá incorrer na propagação de estereótipos da cultura do outro, limitando-se a tratar de aspectos exóticos e/ou festivos em sala de aula. Seu planejamento e os materiais utilizados devem refletir toda a complexidade deste termo, ajudando os alunos a se descobrir e se entender perante o outro. Berwig (2004) critica a maneira de encarar a cultura que ela chama de ilustrada ou enciclopédica e aponta que muitos professores também tratam a cultura como erudição, trabalhando este conceito de forma intuitiva, sem bases científicas. Lamentavelmente, essa equivocada concepção ainda está muito atrelada ao ensino de línguas.

Continuando no grupo de discussão sobre a eficácia dos projetos interculturais desenvolvidos nas escolas, foi perguntado se eles eram pontuais, folclóricos ou de outra maneira, ao que $\mathrm{P} 4$ apontou:

Para aparecer nas fotos, o folclórico está legal e para um relatório também, e para voltar a pedir um financiamento o folclórico também está legal. Então você tem um bom financiamento e tem que dar uma imagem e tem que vender essa imagem. Mas além disso, repercute na dinâmica geral e no que é o dia a dia.
0 professor constrói uma crítica aos projetos que celebram somente a parte folclórica, entretanto entende que, para aparecer ao público, nos relatórios e para pedir financiamento aos órgãos competentes, esse tipo de projeto é bem aceito. Mas ao ser colocado em prática na escola, seria mais uma celebração de aspectos pontuais, conforme apontado anteriormente pelo professor P1, com o exemplo dos mapas com a origem dos alunos.

Matos (2014a) aponta que a dificuldade de trabalhar com questões culturais na sala de aula poderia estar ligada à aceitação e ao entendimento de determinadas definições de cultura. Esses conceitos ainda evocam a ideia de que cultura é somente um "conjunto de conquistas artísticas, intelectuais e morais que constituem o patrimônio de uma nação" (CUCHE, 1999, p. 28). Existe também o entendimento preconceituoso de que a cultura é uma coleção especializada de arte culta e folclore, ou seja, o culto estaria relacionado a determinados tipos de quadros, de músicas e de livros da classe dominante, enquanto que o folclórico englobaria objetos do povo (CANCLINI, 2006). Canclini (2006) ressalta que o conceito de coleção de bens simbólicos utilizado na Europa moderna e, posteriormente na América Latina, tinha como propósito hierarquizar os diferentes grupos e promover desigualdades.

Ainda sobre o plano folclórico, outro professor, P3, comentou que em sua escola são apresentados outros tipos de projetos interculturais:

Não somente folclórico, porque são feitas atividades que não são só folclore, são atividades de leitura, de comentários, de disco-forum ${ }^{4}$, de ... muitas atividades, mas muito pontuais. Dentro de um projeto, uma dinâmica de um ano inteiro, eu gosto de participar em uma coisa assim, na qual você convive na escola gostaria de ter tempo e poder participar, porque temos

4- Realizar um debate, uma reflexão com os alunos, por meio de canções. 
critério e temos experiência e conhecemos as crianças. Mas quando você trabalha em sete escolas, como? (P3).

Percebemos a motivação que tem o professor P3, apontando outras maneiras de trabalhar um projeto intercultural, indo além do folclórico, sendo necessário o trabalho durante todo o ano letivo para que tenha continuidade e possa acompanhar o desenvolvimento e envolvimento dos alunos. Em contrapartida, comentou, quase como um desabafo, que é praticamente impossivel que isso aconteça devido à carga horária que os professores têm nas escolas ATAL, pois, devido à sua condição de itinerância em Cádis, precisam trabalhar em muitas escolas, alguns em até sete. 0 professor P4 complementou, comentando que acredita que deveriam sim participar no tema da interculturalidade nas escolas, mas que "hoje, como está o sistema não, não podemos” (P4).

Para Iglesias e Goenechea (2016), o debate entre ATAL fixa ou itinerante é amplo, abarcando a integração e a inclusão. Quando é fixa, possibilita apoio dentro das aulas e a extensão da educação intercultural a toda a escola, podendo se caracterizar como um modelo mais inclusivo. As itinerantes possuem uma filosofía mais integradora, pois os alunos são escolarizados conjuntamente e recebem atenção especial que ajuda a superar o déficit linguístico. A autora considera que as ATAL fixas são mais apropriadas para o desenvolvimento de uma verdadeira educação intercultural, ainda que entenda que não é apropriado estabelecer ATAL fixas quando o número de alunos estrangeiros é muito pequeno.

Percebemos que para os professores participantes da pesquisa o desenvolvimento de um projeto intercultural é importante e precisa ir além da celebração folclórica de conteúdos pontuais. 0 envolvimento de toda a comunidade escolar, incluindo a equipe de direção e coordenação é um ponto chave, entretanto, os professores devem caminhar juntos na construção do projeto e não ficar alheios ao processo. No tocante aos alunos, todos também precisam estar envolvidos, pois o conhecimento e entendimento de outras culturas passa pelo diálogo entre elas.

Aprender uma língua é uma oportunidade de crescimento, de conhecer outra cultura, de se conhecer por meio do diferente. Segundo Paraquett (2010), quando nos conhecemos e reconhecemos no discurso do outro, podemos realizar mudanças que permitam integrar parte do coletivo que, em princípio, é global. A sala de aula de línguas deve ser encarada como o espaço de encontro com outras culturas, e é nesse encontro que podemos nos conhecer melhor, a partir da diversidade cultural.

\section{Considerações finais}

Os resultados dos questionários e do grupo de discussão evidenciaram a demanda, por parte dos professores, da criação de ações pedagógicas orientadas para a formação com base na educação intercultural, indicando que as discussões sobre essa temática são importantes para a organização de uma escola que promova e entenda o encontro com o outro como parte das relações interculturais. Sendo assim, os educadores devem saber utilizar a potencialidade da diversidade para melhorar a aprendizagem e preparar os alunos para viver em uma sociedade complexa, diversa e multicultural, pois o mundo atual oferece múltiplas oportunidades para a interação ou diálogo entre culturas (MENDES, 2007) e a construção identitária (MOITA LOPES, 2006; HALL, 2006), uma dessas possibilidades de interação se dá por meio da língua em sua dimensão individual e social (MATOS, 2014a).

Uma formação inicial e continuada que tenha como princípio o desenvolvimento da educação intercultural tanto nas escolas que não recebem imigrantes quanto nas que recebem, caso das ATAL, é importante para que sejam elaborados currículos e ações em conformidade com seus pressupostos. Silva (2008, p. 196), ao se referir ao currículo escolar, afirma que 
“o discurso do currículo, pois, autoriza ou desautoriza, legitima ou deslegitima, inclui ou exclui”. É justamente esse discurso que vai nos construir como sujeitos e influenciar no que nos transformamos. Assim, um professor intercultural não pode pensar o currículo somente como uma listagem de itens, mas como algo muito mais amplo que deve abarcar as diversas identidades culturais que circulam em nossa sociedade, as quais estão sendo cotidianamente questionadas (MATOS, 2014b). Nesse contexto, a língua tem um papel central, sendo necessário adquirir uma nova e manter a de origem, como afirmação da identidade dos alunos.

\section{Referências}

AGUADED, Eva María et al. ¿Qué características tiene la educación intercultural que se diseña y aplica en los centros educativos españoles? Revista Qurriculum, Laguna, v. 23, p. 179-201, 2010.

BERWIG, Carla Anéte. Estereótipos culturais no ensino/aprendizagem de português para estrangeiros, 2004, 147 f. Dissertação (Mestrado em Letras) - Universidade Federal do Paraná, Curitiba, 2004.

BESALÚ, Xavier. Diversidad cultural y educación. Madrid: Síntesis, 2002.

CANCLINI, Néstor García. Culturas híbridas: estratégias para entrar e sair da modernidade. São Paulo: Edusp, 2006. p. 283-350.

CORACINI, Maria José. Língua estrangeira e língua materna: uma questão de sujeito e identidade. In: CORACINI, Maria José (Org.). Identidade e discurso: (des)construindo subjetividades. Campinas: Unicamp; Chapecó: Argos, 2003. p. 139-159.

CUCHE, Dennys. A noção de cultura nas ciências sociais. Bauru: Edusc, 1999.

ESPAÑA. Orden de 15 de enero de 2007, por la que se regulan las medidas y actuaciones a desarrollar para la atención del alumnado inmigrante y, especialmente, las Aulas Temporales de Adaptación Lingǘística. B0JA, n. 33, 14 feb. 2007. Disponível em: <http://www.juntadeandalucia.es/boja/2007/33/1>. Acesso em: 10 abr. 2016.

ESPAÑA. Consejería de Educación, Cultura y Deporte. La educación en Andalucía: curso 2014-2015. Datos Avance. Disponível em: <http://www.iseandalucia.es/c/document_library/get_file?uuid=70870ab5-cbb0-4056-81da-2ade3dee246d\&groupld=10137> . Acesso em: 10 abr. 2016.

ESPAÑA. Ministerio de Educación e Ciencia. Ley Orgánica para la Mejora de la Calidad Educativa 8/2013, de 10 de diciembre de 2013. Boletín Oficial del Estado, Madrid, n. 295, p. 97858-97921, 10 dic. 2013. Disponível em: <https://www.boe.es/boe/ dias/2013/12/10/pdfs/BOE-A-2013-12886.pdf>. Acesso em: 10 abr. 2016.

ESPAÑA. Ministerio de Educación, Cultura y Deporte. Estadísticas de las enseñanzas no universitárias: datos avance del curso 2014-15. Disponível em: <http://www.mecd.gob.es/dms/mecd/servicios-al-ciudadano-mecd/estadisticas/educacion/nouniversitaria/alumnado/matriculado/2014-2015/Nota.pdf>. Acesso em: 10 abr. 2016.

ESPAÑA. Ministerio de Educación, Cultura y Deporte. Ley Orgánica de Educación 2/2006, del 3 de mayo de 2006. Boletín Oficial del Estado, Madrid, n. 106, 4 maio 2006. Disponível em: <www.boe.es/boe/dias/2006/05/04/pdfs/A17158-17207.pdf>. Acesso em: 10 abr. 2016.

GRAÑERAS, Monserrat et al. La atención lingüística al alumnado extranjero en el sistema educativo español: normativa, actuaciones y medidas. Revista de Educación, Madrid, n. 343, p. 149-174, 2007.

HALL, Stuart. A identidade cultural na pós-modernidade. Traduzido por Tomaz Tadeu da Silva e Guacira Lopes Louro. 11. ed. Rio de Janeiro: DP\&A, 2006.

IGLESIAS, Cristina; GOENECHEA, Cristina. La itinerancia como rasgo distintivo del profesorado de las ATAL de Cádiz. In: CIMIE: Educational Research With Social Impact, 16., 2016, Sevilla. Libro de comunicaciones. Sevilla: CIMIE, 2016. No prelo. 
JIMÉNEZ GÁMEZ, Rafael Ángel (Coord.). Estudio de la atención educativa prestada al alumnado inmigrante en las aulas temporales de adaptación lingüística de Cádiz. Cádiz: Universidad de Cádiz, 2009.

JIMÉNEZ GÁMEZ, Rafael Ángel; GOENECHEA, Cristina. Educación para una ciudadanía intercultural. Madrid: Síntesis, 2014.

LÓPEZ REILLO, Paloma. Una oportunidad para aprender: la dimensión intercultural en la formación del profesorado. Tenerife: Cabildo Insular de Tenerife, Área de Desarrollo Económico, 2006.

MATOS, Doris Cristina Vicente da Silva. Formação intercultural de professores de espanhol: materiais didáticos e contexto sociocultural brasileiro, 2014. Tese (Doutorado em Letras) - Universidade Federal da Bahia, Salvador, 2014a.

MATOS, Doris Cristina Vicente da Silva. Formação Intercultural de Professores de Espanhol e Materiais Didáticos. Abehache: Revista da Associação Brasileira de Hispanistas, São Paulo, v. 1, p. 165-185, 2014 b.

MENDES, Edleise. A perspectiva intercultural no ensino de línguas: uma relação "entre- culturas". In: ALVAREZ, Maria Luísa Ortiz; SILVA, Kleber Aparecido da. Lingüística aplicada: múltiplos olhares. Campinas: Pontes, 2007. p. 119-139.

MOITA LOPES, Luiz Paulo. Por uma lingüística aplicada indisciplinar. São Paulo: Parábola, 2006.

PARAQUETT, Marcia. Multiculturalismo, interculturalismo e ensino/aprendizagem de español parabrasileiros. In: COSTA, Elzimar Goettenauer Martins; BARROS, Cristiano Silva (Org.). Coleção explorando o ensino. Brasília, DF: Ministério da Educação, 2010. p. $137-156$

SILVA, Tomaz Tadeu da. Currículo e identidade social: territórios contestados. In: SILVA, Tomaz Tadeu da (Org.). Alienígenas na sala de aula: uma introdução aos estudos culturais em educação. Petrópolis: Vozes, 2008. p. 190-207.

TERRÓN-CARO, Teresa; PALMA, Verónica Cobano-Delgado. Interculturalidad e inclusión del alumnado marroquí en educación primaria de Andalucía. Educação e Pesquisa, São Paulo, v. 41, n. 1, p. 101-117, mar. 2015.

Recebido em: 19.04.2016

Aprovado em: 09.08.2016

Doris Cristina Vicente da Silva Matos é doutora em língua e cultura (UFBA), mestre em letras (Linguística aplicada ao ensino/aprendizagem de espanhol LE - UFF), especialista em língua espanhola instrumental para leitura (UERJ) e graduada em letras português/espanhol (UFF). É professora adjunta do Departamento de Letras Estrangeiras da Universidade Federal de Sergipe (UFS) e líder do Grupo de Pesquisa DInterLin: Diálogos Interculturais e Linguísticos.

Cristina Goenechea Permisán é doutora em ciências da educação pela Universidad de Santiago de Compostela e licenciada em psicopedagogia pela Universidad de Navarra. É professora contratada doutora do Departamento de Didáctica da Faculdade de Ciências da Educação da Universidad de Cádiz (Espanha). Pertence ao Grupo de Pesquisa Eduardo Benot HUM 230. 